\title{
Quadricuspid aortic valve associated with hypoplastic aortic annulus
}

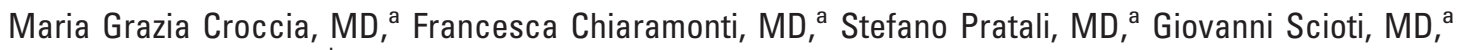 \\ Fabio Guarracino, MD, ${ }^{\mathrm{b}}$ and Uberto Bortolotti, MD, ${ }^{\mathrm{a}}$ Pisa, Italy
}

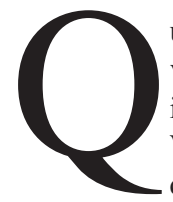

uadricuspid aortic valve is a rare anomaly leading to valve replacement usually because of aortic valve insufficiency and rarely because of pure stenosis. ${ }^{1,2}$ We describe the previously unreported association of quadricuspid aortic valve and hypoplastic aortic annulus, emphasizing the need for a more complex surgical procedure.

\section{Clinical Summary}

A 29-year-old man with a known diagnosis of bicuspid aortic valve was referred to our unit for evaluation because of the recent onset of exertional dyspnea. On admission, the electrocardiogram showed sinus rhythm and signs of left ventricular hypertrophy. On physical examination, a systo-diastolic murmur was audible on the aortic area. A transthoracic 2-dimensional echocardiogram revealed a fibrotic, most likely bicuspid, aortic valve with a peak gradient of $62 \mathrm{~mm} \mathrm{Hg}, 3+$ regurgitation, and moderate dilatation of the ascending aorta $(45 \mathrm{~mm})$. Angiographic scanning showed normal coronary arteries. In October 2006, the patient was scheduled for aortic valve replacement. At operation, a transesophageal echocardiogram confirmed the severity of valve disease but revealed a quadricuspid aortic valve (Figure 1). Standard cardiopulmonary bypass was instituted with moderate hypothermia, and the heart was arrested with cold-blood cardioplegic solution infused into the coronary ostia. Through a transverse aortotomy, the aortic valve, which was quadricuspid with two equal larger cusps and two equal smaller cusps (Figure 2), was excised, leaving a diminutive aortic annulus of $19 \mathrm{~mm}$. Potential patient-prosthesis mismatch was avoided by enlarging the aortic annulus with a patch of bovine pericardium, as previously described, ${ }^{3}$ which was cut to match the proximal aortic rim. This allowed the insertion of a 23-mm CarboMedics bileaflet prosthesis (Sulzer CarboMedics, Inc, Austin, Tex) with multiple stitches reinforced by subannular Teflon pledgets. Part of the dilated ascending aorta was also resected and its continuity reconstructed by end-to-end anastomosis. The patient recovered uneventfully and he is currently free of symptoms 8 months postoperatively.

From the Section of Cardiac Surgery ${ }^{\mathrm{a}}$ and Division of Anesthesiology, ${ }^{\mathrm{b}}$ Cardiac Thoracic and Vascular Department, University of Pisa Medical School, Pisa, Italy.

Received for publication June 25, 2007; accepted for publication July 5, 2007.

Address for reprints: Uberto Bortolotti, MD, Sezione Autonoma di Cardiochirurgia Universitaria, Dipartimento Cardio Toracico e Vascolare, Ospedale Cisanello, Via Paradisa 2, 56124 Pisa, Italy (E-mail: u.bortolotti@ cardchir.med.unipi.it).

J Thorac Cardiovasc Surg 2007;134:1061-2

$0022-5223 / \$ 32.00$

Copyright $@ 2007$ by The American Association for Thoracic Surgery

doi:10.1016/j.jtcvs.2007.07.007

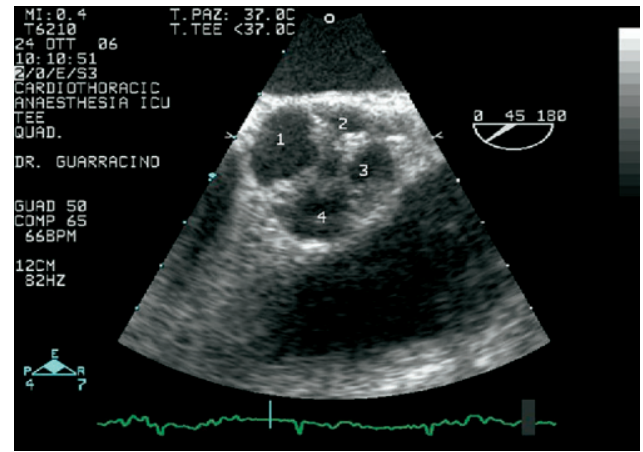

Figure 1. Transesophageal short-axis view at $45^{\circ}$ showing a quadricuspid aortic valve.

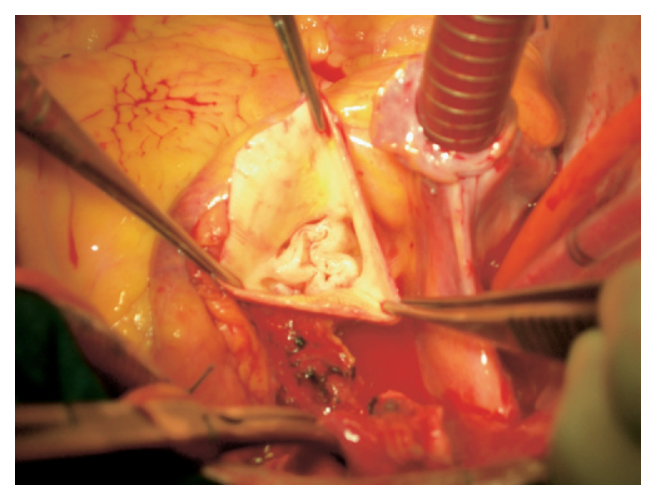

Figure 2. Intraoperative view demonstrating a fibrotic quadricuspid aortic valve and dilatation of the ascending aorta.

\section{Discussion}

Quadricuspid aortic valve is a rare congenital lesion that is currently diagnosed with increasing frequency because of the routine use of echocardiography in clinical practice. In a recent review of the literature, Turatel ${ }^{4}$ identified a total of 186 such cases reported so far. In this setting, incompetence is the leading cause of failure inasmuch as such valves are more prone to endocarditis and to the development of progressive cusp fibrosis and calcification at an earlier stage because of unequal distribution of mechanical stresses. ${ }^{5}$ Identification of such patients is therefore crucial to provide an adequate follow-up, which must include periodic echocardiographic assessments and prophylaxis against endocarditis. It must, however, be underlined that transthoracic echocardiography may at times fail to detect such anomaly. Indeed, preoperative echocardiographic diagnosis is facilitated in the presence of four 
cusps of equal size, whereas other anatomic patterns, as in our case, are more difficult to detect. This explains why many cases of quadricuspid aortic valves are still occasional surgical or necropsy findings. ${ }^{4,5}$

In our patient, a quadricuspid aortic valve, which may be identified as type $\mathrm{C}$ according to the Hurwitz-Roberts classification, ${ }^{1}$ was associated with a hypoplastic aortic annulus. This finding, not previously recognized even in a comprehensive review, ${ }^{4}$ required a more technically demanding surgical procedure. The present case illustrates such an unusual combination, indicating that occasionally a quadricuspid aortic valve may be part of a more complex pathologic condition of the left ventricular outflow tract.

\section{References}

1. Hurwitz LE, Roberts WC. Quadricuspid semilunar valves. Am J Cardiol. 1973; 31: 623-6.

2. Mecozzi G, Pratali S, Milano A, Nardi C, Bortolotti U. Severe quadricuspid aortic valve stenosis after mediastinal irradiation. J Thorac Cardiovasc Surg. 2003;126:1198-9.

3. Bortolotti U, Scioti G, Milano A, Nardi C, Tartarini G. Enlargement of the aortic annulus with glutaraldehyde-fixed bovine pericardium during aortic valve replacement. J Heart Valve Dis. 1998;7:299-304.

4. Turatel $\mathrm{O}$. The quadricuspid aortic valve: a comprehensive review. J Heart Valve Dis. 2004;13:534-7.

5. Jannssens U, Klues HG, Hanrath P. Congenital quadricuspid aortic valve anomaly associated with hypertrophic non-obstructive cardiomyopathy: a case report and review of the literature. Heart. 1997;78:83-7.

\section{Repair for a duplicate mitral valve with torn chordae}

Kohei Ando, MD, Yukihiro Tomita, MD, Munetaka Masuda, MD, Atsuhiro Nakashima, MD, and Ryuji Tominaga, MD, Fukuoka, Japan

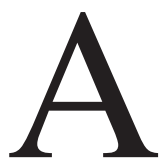

duplicate mitral valve is especially uncommon in patients with double-orifice mitral valve (DOMV). ${ }^{1} \mathrm{We}$ herein report a case demonstrating an isolated duplicate mitral valve with a torn chordae in which mitral valvuloplasty was undertaken successfully.

\section{Clinical Summary}

A 46-year-old male patient with severe mitral regurgitation (MR) was admitted to our department. He had had dyspnea for 5 months, which had gradually worsened over time. A regurgitant systolic murmur, grade $4 / 6$, was audible at the apex. Left ventricular angiography showed severe grade 4/4 MR. An echocardiogram indicated a diagnosis of torn chordae at the posteromedial scallop of the posterior mitral leaflet.

A preoperative Doppler echocardiogram showed the area of the two mitral orifices to measure $5.5 \mathrm{~cm}^{2}$ in size on the posteromedial side and $2.4 \mathrm{~cm}^{2}$ in size on the anterolateral side (Figure 1). Severe MR caused by torn chordae was found only from the lateral mitral valve. The tissue separating the two orifices looked stiff, in contrast to the fibrous string connecting the two leaflets. The chordae of the two mitral valves were folded into each of the papillary

From the Department of Cardiovascular Surgery, Faculty of Medicine, Kyushu University, Fukuoka, Japan.

Received for publication Jan 18, 2007; revisions received March 21, 2007; accepted for publication April 20, 2007.

Address for reprints: Yukihiro Tomita, MD, Associate Professor, Department of Cardiovascular Surgery, Faculty of Medicine, Kyushu University, 3-1-1 Maidashi, Higashi-ku, Fukuoka 812-8582, Japan (E-mail: tomita@ heart.med.kyushi-u.ac.jp).

J Thorac Cardiovasc Surg 2007;134:1062-3

$0022-5223 / \$ 32.00$

Copyright @ 2007 by The American Association for Thoracic Surgery doi:10.1016/j.jtcvs.2007.04.036 muscles, on the posteromedial and anterolateral sides. As a result, the two mitral valves seemed to be independent of each other, including the subvalvular apparatus. Other findings were as follows: the left ventricular ejection fraction was $59 \%$ and the tricuspid regurgitation was grade 2 .

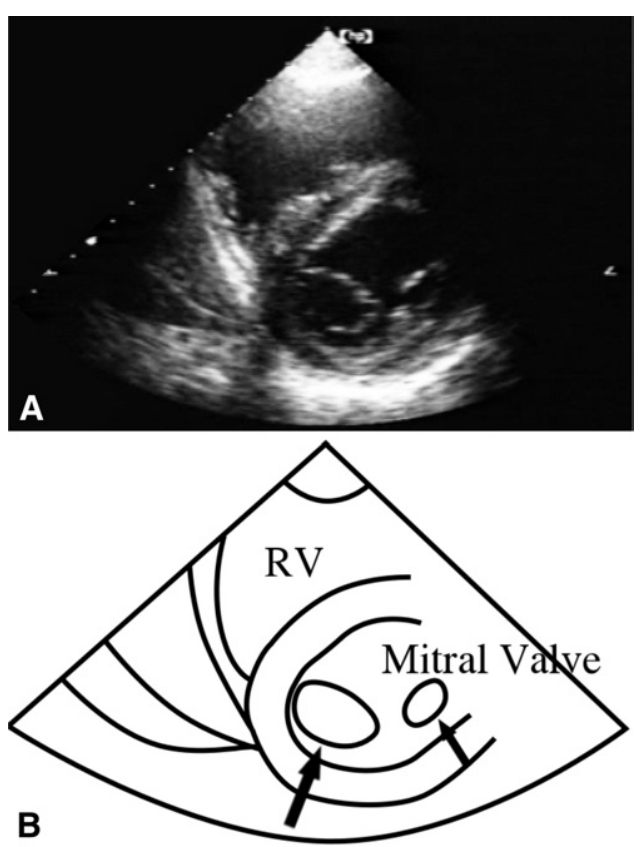

Figure 1. Two-dimensional echocardiogram showing duplicate mitral valve. Short-axis view of left ventricle. Two mitral valve orifices are shown. The posteromedial orifice (large arrow) is larger than the anterolateral one (small arrow). Right ventricular overload is also observed (flattening of ventricular septal wall). 